\begin{abstract}
Iranica
Abstracta Iranica Revue bibliographique pour le domaine irano-aryen

Volume 34-35-36 | 2017

Comptes rendus des publications de 2011-2013
\end{abstract}

\title{
Farhad Daftary. A History of Shi'i Islam
}

\section{Mathieu Terrier}

\section{(2) OpenEdition \\ Journals}

Édition électronique

URL : http://journals.openedition.org/abstractairanica/42402

DOI : 10.4000/abstractairanica.42402

ISSN : 1961-960X

Éditeur :

CNRS (UMR 7528 Mondes iraniens et indiens), Éditions de l'IFRI

\section{Référence électronique}

Mathieu Terrier, «Farhad Daftary. A History of Shi'i Islam », Abstracta Iranica [En ligne], Volume 34-35-36 | 2017, document 7, mis en ligne le 30 juillet 2017, consulté le 30 septembre 2020. URL : http://journals.openedition.org/abstractairanica/42402 ; DOI : https://doi.org/10.4000/ abstractairanica.42402

Ce document a été généré automatiquement le 30 septembre 2020.

Tous droits réservés 


\title{
Farhad Daftary. A History of Shi $i$ Islam
}

\author{
Mathieu Terrier
}

\section{RÉFÉRENCE}

Farhad Daftary. A History of Shiti Islam. London, I.B. Tauris, in association with The Institute of Ismaili Studies, 2013, 315 p. [ISBN: 978178076841 0]

1 Signé d'un des plus grands spécialistes de l'ismaélisme, ce livre propose une histoire générale du shi'isme tant sur le plan chronologique que doctrinal. L'introduction (chap. 1) présente l'évolution de l'historiographie occidentale du shi'isme et son émancipation progressive de l'hérésiographie sunnite. Le chap. 2 retrace les origines et la formation du shi'isme, rappelant que l'imâmisme proto-duodécimain ne devint majoritaire qu'après la révolution 'abbasside. Les quatre chapitres suivants, de longueur décroissante, traitent respectivement des quatre branches subsistant aujourd'hui : l'imâmisme, l'ismaélisme, le zaydisme et le nuṣayrisme-'alawisme.

2 Le chap. 3 rappelle la construction du shi'isme aux douze imâms, de sa doctrine de l'occultation et du retour de l'imâm. Il retrace l'histoire de l'imâmisme en cinq phases : 1) la période des imâms historiques ; 2) celle de l'occultation (« mineure » en $260 / 874$, « totale " en 329/941) à l'époque bouyide, marquée par la montée en puissance des 'ulam $\bar{a}$ ' 3) le repli après la reprise en main sunnite de l'empire et une nouvelle progression après l'invasion mongole ; 4) la constitution d'un clergé rationaliste et la renaissance philosophique sous les Safavides en Iran ; 5) de 1800 à nos jours, le triomphe des rationalistes ușūlī et la politisation de l'imâmisme, ainsi que l'émergence de mouvements hétérodoxes comme les šayHī et les bahā’

3 Le chap. 4 commence par présenter la fondation de l'ismaélisme avec un parti-pris favorable. Il analyse ensuite : 1) la phase de formation, avec une organisation centralisée et une doctrine messianique ; 2) la politisation de l'ismaélisme avec la séparation de la branche fatimide et de la dissidence qarmate ; 3) la période du califat 
fatimide ; 4) les nouvelles divisions du Ve/XI $\mathrm{e}$. avec l'apparition des futurs Tayyibides et des Nizarites ; 5) l'ismaélisme postérieur à la destruction du royaume fatimide en 567/1171 et à celle de l'État nizarite d'Alamūt en 654/1256, avec son déplacement en Inde puis en Europe à la période moderne.

4 Le chap. 5 nous éclaire sur le shi'isme zaydite, ainsi nommé d'après leur quatrième imâm. L'A. souligne le paradoxe du zaydisme originel, plus militant sur le plan politique mais plus modéré sur le plan doctrinal que les autres courants shi'ites. L'histoire du zaydisme est retracée dans les deux zones géographiques qui l'ont abrité : la région de la mer caspienne au nord de l'Iran jusqu'à la fin du $\mathrm{X}^{\mathrm{e}} / \mathrm{XVI}^{\mathrm{e}} \mathrm{s}$., et le Yémen jusqu'au $\mathrm{XIV}^{\mathrm{e}} / \mathrm{XX}^{\mathrm{e}}$ siècle.

5 Enfin, le chap. 6 est consacrée au courant longtemps méconnu du nuṣayrisme-'alawisme. Sa singularité est d'avoir conservé des conceptions théologiques des premiers " exagérateurs » (g்lāt), d'où son caractère particulièrement ésotérique. L'A. retrace l'histoire des nușayrites en Syrie depuis le $\mathrm{V}^{\mathrm{e}} / \mathrm{XI}^{\mathrm{e}} \mathrm{s}$., leurs confrontations avec les ismaéliens nizarites et les druzes, leur relative autonomie au sein de l'empire ottoman, leur choix du nom de 'alawites au début du $\mathrm{XX}^{\mathrm{e}}$ pour mettre en avant leur shi'isme.

6 Un glossaire, un riche appareil de notes et une bibliographie fournie rehaussent encore la valeur de l'ouvrage tant aux yeux du chercheur spécialisé que d'un large public.

\section{AUTEURS}

\section{MATHIEU TERRIER}

Paris 